\title{
Comportamento do Consumidor em Canais Cruzados: Modelo de Mediação-Moderada nas Compras Online/Offline
}

\author{
Cross Channel Consumer Behavior: A Moderate-Mediation Model in Online/Offline \\ Purchasing
}

\begin{abstract}
Sionara Okada ${ }^{1}$
Rafael Porto ${ }^{1}$

Universidade de Brasília, Departamento de Administração, Brasília, DF, Brasil ${ }^{1}$
\end{abstract}

Artigo recebido em 14.02.2017. Última versão recebida em 30.03.2018. Aprovado em 13.04.2018. 


\title{
Resumo
}

As novas tecnologias móveis com acesso à internet têm propiciado o surgimento de um novo processo de compra dos consumidores. Esse processo influencia tanto as compras online quanto as offline (em lojas físicas), a depender do produto a ser adquirido. Teorias de aprendizagem comportamental, como as relações entre precorrentes e correntes, podem explicar esse novo repertório comportamental. O presente estudo testou a mediação do Comportamento em Canais Cruzados (CCC) na relação entre a adoção de dispositivos móveis com acesso à internet e a frequência de compra nos canais online e offline, moderada pelo tipo de bem (durável versus não durável). Com delineamento quase experimental, os dados foram analisados por Modelagem de Equação Estrutural. Os resultados demonstram que a adoção de tecnologias móveis com internet incentivou as dimensões do CCC (busca de informação simultânea, comparação de produtos e preços, e interação com o varejista/fabricante), com maior força para bens não duráveis, e que cada dimensão do CCC altera a frequência de compras online e offline, porém, o efeito específico depende do tipo do bem. A pesquisa analisa o processo de adoção de novas tecnologias geradoras destes novos comportamentos, e que os mesmos incentivam a frequência de compra.

Palavras-chave: comportamento do consumidor; canais de compra; adoção de tecnologia; aprendizagem.

\begin{abstract}
Mobile technologies with internet access have led to the emergence of a new consumer buying process. This process influences online and offline (physical store) purchases, depending on the product to be purchased. Behavioral learning theories, such as the relationships between precurrent and current behaviors, can explain this new behavioral repertoire. The present study tested Cross Channel Behavior mediation (CCB) on the relationship between mobile device adoption with internet access and the frequency of purchase in online and offline channels, moderated by the types of goods (durable vs. non-durable). Through a quasi-experimental design, data were analyzed by Structural Equation Modeling. The results demonstrate that the adoption of mobile technologies has encouraged the occurrence of $\mathrm{CCB}$ dimensions (simultaneous search for information, price and product comparisons, and interaction with retailers/producers), with greater strength for non-durable goods, and that each CCB dimension changes the frequency of online and offline purchases, but the specific effect depends on the type of good. The research analyzes the process of new technologies adoption that generate new behaviors and that these encourage purchase frequency.
\end{abstract}

Key words: consumer behavior; purchase channels; technology adoption; learning; mediation-moderation.

JEL Classification Codes: C91, D12, L86. 


\section{Introdução}

O processo de compra dos consumidores tem se alterado nos últimos anos devido à adoção de tecnologias móveis com acesso à internet (Wang, Malthouse, \& Krishnamurthi, 2015). Se em tempos anteriores as compras poderiam ocorrer apenas em um canal (ou na loja física ou na loja virtual), em tempos recentes esse processo pode ocorrer simultaneamente nos dois canais (online e offline). Assim, um consumidor em uma loja física se interessa por um produto e, com seu smartphone, acessa a internet, buscando mais informação acerca desse produto. Por sua vez, outro consumidor está em uma loja virtual, acessa outro sítio eletrônico que permita comparação de preços, compara o preço do produto interessado e se direciona a uma loja física para efetuar a compra. Esses são dois exemplos de comportamentos que ilustram que o processo de compra tem se alterado e tem modificado as vendas dos produtos.

Essa nova forma de comprar tem sido chamada de Comportamento em Canais Cruzados (CCC), que se refere ao uso alternado e/ou simultâneo de canais online e offline, em um processo de compra (Gerritsen et al., 2014; Trenz, 2015). O CCC se insere em um movimento de transição do varejo multicanal para o Ominichannel (Avery, Steenburgh, Deighton, \& Caravella, 2012; Gensler, Leeflang, \& Skiera 2012; Pauwels, Leeflang, Teerling, \& Huizingh, 2011; Van Nierop, Erjen, Leeflang, Teerling, $\&$. Huizingh, 2011) que alguns autores consideram como uma mudança disruptiva do varejo e uma mudança moderada do comportamento do consumidor (Verhoef, Kannan, \& Inmanc, 2015). Outros autores (Xu, Forman, Kim, \& Van Ittersum, 2014) reiteram que a utilização de canais móveis, especificamente os aplicativos de compras para smartphones/tablets inauguraram o varejo Ominichannel por terem afetado o comportamento do consumidor e, consequentemente, as atividades do varejista.

Infelizmente, a literatura de adoção à tecnologia não traz muitos indícios do que ocorre após a adoção. As pesquisas concentram-se em seus antecedentes e não nos consequentes da adoção (Sanakulov \& Karjaluoto, 2015). Isso demanda uma nova abordagem de estudo sobre os possíveis consequentes da adoção de tecnologias: se o consumidor assimila, como ele usa, que experiências ele adquire, etc. Especificamente, poucas pesquisas se concentraram na detecção do processo alternado de compra em si (Verhoef et al., 2015), uma das consequências da adoção de tecnologias móveis com acesso à internet. Se ele se alterou, uma possível modificação na frequência de compra seria esperada, já que uma maior facilidade do processo de compra (consultar em tempo real e comprar em múltiplas plataformas) poderia estimular/desestimular essa frequência.

Além disso, o processo de compra de um bem não durável pode ser diferente de um bem durável se alterar os canais de compra offline e online (Campo \& Breugelmans, 2015). No Brasil, em termos gerais, para comprar bens duráveis em loja física, os consumidores precisam da interação com o vendedor, enquanto no canal online isso não é necessário. Já para os bens não duráveis no canal offline, o consumidor precisa passar em corredores ou ficar de frente às prateleiras, enquanto no canal online isso não é necessário.

Sabe-se que bens com ciclo de duração longo (bens duráveis) têm maior êxito de comercialização em canais online e bens com ciclo de duração curto (bens não duráveis) têm maior êxito nos canais físicos (Nakayama \& Sutcliffe, 2009; Pauwels \& Neslin, 2015). Entretanto, não se conhece a influência do tipo de bem comprado com a incorporação do CCC no repertório comportamental previamente aprendido pelo consumidor.

Dessa maneira, tornou-se necessário investigar se a compra de diferentes tipos de bens afeta tanto a relação entre a adoção de dispositivos móveis com acesso à internet e o CCC, quanto a relação entre o CCC e a frequência de compra nos canais online e offline. $\mathrm{O}$ objetivo deste artigo é investigar se a mediação do comportamento em canais cruzados na relação entre a adoção de dispositivos móveis com acesso à internet e a frequência de compra sofre influência moderadora do tipo de bem a ser adquirido. Para tanto, recorreu-se à literatura de aprendizagem, em específico, às teorias de respostas precorrentes e correntes para explicar a incorporação desse novo repertório comportamental nas experiências dos consumidores. 


\section{Relação Resposta-Resposta: Como os Consumidores Aprendem a Comprar}

O comportamento em canais cruzados é multifacetado e pode abranger comportamentos mistos online e offline na busca de informações simultâneas, de comparação de produtos/preços e de interação entre consumidor e varejista/fabricante (Gerritsen et al., 2014; Porto \& Okada, 2018). Os dois primeiros são mais típicos de ocorrerem na etapa de pré-compra e a última pode ocorrer durante todo o processo de compra, estendendo-se desde a pré-compra, passando pela compra efetiva até a etapa de pós-compra.

Um tipo de comportamento de canais cruzados chamado de passeio gratuito tem sido considerado como gerador de consequências ruins para os varejistas por erodir suas vendas (Chiu, Hsieh, Roan, Tseng, \& Hsieh, 2011; Heitz-Spahn, 2013). Ele incentiva a procura de informação em uma cadeia lojista, mas o consumidor efetua a compra em outra cadeia varejista. Isso tem apresentado implicações em discussões sobre taxas de retenção de clientes e lealdade do consumidor ao canal (Van Baal \& Dach, 2005).

Entretanto, um olhar mais amplo, abarcando o conjunto de comportamentos de uso alternado de canais online e offline em um processo de compra, pode ser útil para revelar seu lado positivo. Se pelo lado do varejista ele é maléfico, pelo lado do consumidor deve ser benéfico. Se um comportamento é frequente, como tem sido sugerida sua maior ocorrência nos tempos atuais (Doong, Wang, \& Foxall, 2011), há um conjunto de situação que o induz e um conjunto de consequentes que mantêm esse comportamento (Skinner, 2013). Dessa forma, identificar essas situações e a relação desse comportamento com outros já investigados na área de consumo pode ser um caminho frutífero para revelar seus benefícios.

A busca por informação simultânea, a comparação de produtos/preços e a interação com o varejista/fabricante podem ser considerados como comportamentos precorrentes auxiliares não requeridos pela situação de compra (Pohl \& Oliveira-Castro, 2008). Essa situação é formada pela contingência de três termos: estímulo resposta $\rightarrow$ reforço/punição (Skinner, 2013). Dessa maneira, na presença de estímulo discriminativo (também chamado de contexto), uma resposta (comportamento) é emitida(o) e esta(e) gera consequência no ambiente. Ao longo do tempo, essa consequência pode retroalimentar a contingência e, por meio de relações sistemáticas entre a consequência e o estímulo, o indivíduo aprende que o contexto pode sinalizar que determinada consequência poderá ocorrer.

Tipicamente averiguadas em pesquisas sobre resolução de problema da área de aprendizagem em processos de tomada de decisão, o comportamento faz parte de uma cadeia comportamental (Skinner, 2013). A solução de um problema implica na emissão de respostas, chamadas precorrentes (ou preliminares), que tornam a resposta solução mais provável. Por exemplo, para encontrar a solução de um problema de contagem ou multiplicação de números (Aggio, Postalli, \& Garcia, 2016), uma criança pode fazer cálculos usando seus dedos (precorrente) para que apresente uma resposta final do valor final da contagem (corrente). Essa criança aprende então a calcular através de um método (conjunto de precorrentes).

De forma similar, para saber se compensa comprar um produto, um consumidor pode calcular a diferença de preços, comparar informações, pedir mais informação ao vendedor, etc. Essas respostas prévias do ato da compra podem tornar a compra mais provável, podendo torná-la também mais eficiente. $\mathrm{O}$ consumidor dessa forma iria se aperfeiçoando a cada vez que ele realizasse o mesmo tipo de comportamento para o mesmo produto. Ele melhoraria seu desempenho enquanto consumidor se adotar precorrentes que auxiliam esse aperfeiçoamento.

Comportamentos precorrentes são "respostas que aumentam a frequência de outras respostas ocorrerem ou serem reforçadas" (Pohl, Oliveira-Castro, Bertoldi, \& Lourenzo, 2006, p. 240). Ou seja, são respostas preliminares que aumentam a frequência de outras respostas ocorrerem, chamada de corrente (ex: compra do produto) que podem ser reforçadas (Oliveira-Castro, Faria, Dias, \& Coelho, 2002). O CCC, nessa concepção, passa a ser uma estratégia pessoal de aperfeiçoamento do alcance de uma resposta subsequente como a compra, tradicionalmente investigada na área de marketing 
(Nadarajah \& Kotz, 2009). Se o produto traz utilidade ao consumidor, essa utilidade pode estimular toda a cadeia de comportamentos executada previamente em uma próxima compra (Foxall, 2015). Assim, se precisar comprar novamente, o consumidor que conseguiu usufruir da utilidade do produto pode buscar informação alternadamente nos canais online e offline, comparar preços, interagir com o varejista ou fabricante e, mais uma vez, adquirir o mesmo produto.

Mas os precorrentes auxiliares não são requeridos pela contingência de três termos (Skinner, 2013) para executar o comportamento final (ex: comprar), já que o consumidor pode comprar sem nenhuma busca de informação, comprar sem comparar produtos/preços ou não interagir com o varejista/fabricante. No entanto, é pouco provável que as compras ocorram sem que o consumidor tenha executado algum desses comportamentos.

Em ambientes complexos como são os ambientes de lojas físicas e online, há um conjunto de estímulos que caracterizam um contexto propiciador da compra (Foxall, 2015). Quando esse contexto prediz a consequência da resposta do consumidor, diz-se que esse consumidor está sob o controle de estímulo. Portanto, o controle de estímulo é uma tarefa fundamental do ambiente de compra/venda, que geralmente é feita em conjunto principalmente com o varejista e o fabricante, para propiciar às vendas (Porto \& Oliveira-Castro, 2016).

Porém, o ambiente de compra não é só determinado pelos ofertantes. Os consumidores voluntariamente podem acrescentar mais estímulos a ele. Por exemplo, um consumidor que leva seu smartphone para o ponto de venda e o utiliza para comparar preço acessando a internet, está acrescentando mais um estímulo não controlado pelos fabricantes ou varejistas ao ambiente. Mesmo que sítios eletrônicos com e-commerce pertençam a outros varejistas ou fabricantes, o consumidor voluntariamente opta por acessá-los quaisquer que eles sejam. Dessa forma, ele emite uma resposta de adotar uma tecnologia no ponto de venda que estimula outra resposta (de procurar preços online) e que o incita a emitir outro comportamento (ex: comprar). Percebe-se então que há uma cadeia de relação entre comportamentos, alguns sendo precorrentes de outros, até a resposta final (corrente).

A maior função do comportamento precorrente é construir estímulos discriminativos que regulem ações subsequentes (Pierce \& Cheney, 2013). Os consumidores aprendem a emitir esses comportamentos para executar melhor uma reposta final. Como podem ocorrer outros comportamentos prévios, em princípio, o CCC é um precorrente auxiliar não exigido pela contingência de três termos, mas adotar o dispositivo móvel é um precorrente requerido pela contingência para procurar preço da mercadoria em outras lojas. Estando sozinho já dentro de uma loja física, só tem como o consumidor procurar preço em outros pontos de venda sincronicamente ou buscar informações adicionais se ele usar alguma tecnologia com acesso à internet. Portanto, adotar dispositivos móveis com acesso à internet é um precorrente requerido para executar o CCC, e o CCC é um precorrente não requerido para realizar a compra.

O processo de compra de uma mercadoria pelo consumidor até a primeira década do século XXI era controlado pelo ambiente do varejista e/ou fabricante (Antéblian, Filser, \& Roederer, 2013), sendo o consumidor praticamente passivo ao que era exposto pelos ofertantes. No entanto, a adoção de tecnologia móvel com acesso à internet (Wang et al., 2015) tem modificado o processo de compra, propiciando a realização de novos comportamentos dos consumidores. Esses comportamentos são topograficamente novos e não funcionalmente novos (Pierce \& Cheney, 2013). Ou seja, a tecnologia móvel tem alterado as características físicas de como se faz o processo de compra e não altera (pelo menos de forma visível) o propósito para que se faz isso.

Por um instante, a busca de informação, a comparação de produtos/preços e a interação do consumidor com varejista/fabricante são comportamentos feitos mesmo antes do advento da internet e de dispositivos móveis (Singley \& Williams, 1995), mas com eles se ganhou um novo impulso (HeitzSpahn, 2013). Portanto, o propósito de executar o CCC não se alterou: consumidores continuam fazendo tais atividades antes de efetuar uma compra. O que altera é a forma como isso é feito. Consumidores, antes de efetuar a compra, agora podem pegar um dispositivo móvel, acessar um sítio eletrônico que relate a reputação do fabricante e, após isso, decidir se compensa efetuar a compra. Em tempos 
anteriores, isso só seria possível se a reputação de empresas fosse divulgada em massa, se o consumidor visitasse previamente cada loja física ou se recebesse indicação de conhecidos. Nesse sentido, consumidores estão aprendendo ou reaprendendo a como realizar o processo de compra em canais cruzados, incorporando essa nova aprendizagem em seu repertório comportamental previamente aprendido.

Mas esse processo de compra não é similar para bens duráveis e não duráveis no canal online ou offline (Campo \& Breugelmans, 2015). O CCC, portanto, pode ter um papel diferente ao usar canais distintos. Os indivíduos, ao adquirirem um eletrodoméstico no canal online, não precisam necessariamente interagirem com um vendedor. Já se comprarem no canal offline, eles atuam de forma menos autônoma, com um vendedor que opera os procedimentos de compra, checagem de pagamento e de entrega. Além disso, lojas físicas de bens duráveis não têm muita variedade de marcas disponíveis, o que, para lojas que comercializam bens não duráveis, é muito mais recorrente. Os CCC para os bens duráveis podem ser mais úteis ao consumidor para possíveis consultas de preços em outros pontos de venda do que para os bens não duráveis.

Por outro lado, os bens não duráveis são tipicamente comercializados em supermercados, farmácias ou mercearias (Dunne, Lusch, \& Carver, 2013) que já têm muitas marcas concorrentes dentro do mesmo ponto de venda. Essas compras são mais corriqueiras (Oliveira-Castro, Ferreira, Foxall, \& Schrezenmaier, 2005), e o CCC deve ocorrer com maior frequência nessas situações. Assim, os consumidores de bens não duráveis podem necessitar de mais informação desses produtos na loja física do que quando compram online, em especial porque no canal offline não são disponibilizadas informações suficientes sobre cada marca, reputação de empresas, etc. Já se esses consumidores participarem do processo de compra online, basta abrir outra tela do navegador e procurar por informações extras. Então, além de ser mais corriqueira a compra (e a adoção do CCC), o esforço da procura é menor (Jiang, Yang, \& Jun, 2013). Dessa forma,

$\mathbf{H}_{1}$ : Adotar dispositivos móveis com acesso à internet aumenta a ocorrência de comportamentos do consumidor de canais cruzados, com maior intensidade para bens não duráveis do que para bens duráveis.

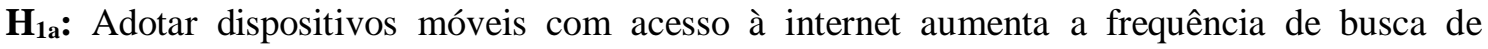
informação simultânea, com maior intensidade para bens não duráveis do que para bens duráveis.

$\mathbf{H}_{1 \mathbf{b}}$ : Adotar dispositivos móveis com acesso à internet aumenta a frequência de comparações de produtos e preços, com maior intensidade para bens não duráveis do que para bens duráveis.

H1c: Adotar dispositivos móveis com acesso à internet aumenta a frequência de interação de varejista/fabricante, com maior intensidade para bens não duráveis do que para bens duráveis.

No entanto, enquanto a relação do antecedente do CCC deve incentivá-lo, as relações das dimensões do CCC com as consequentes, frequência de compra online e offline, dependem substancialmente do conteúdo delas. Ou seja, consumidores que comparam produtos e preços devem aumentar a frequência de compra (tanto online quanto offline), em especial de bens duráveis. Isso porque a comparação de preço é mais útil nessa situação pelo alto preço do bem (Stone, Hobbs, \& Khaleeli, 2002) e também porque existem menos opções de marcas desses bens do que de bens não duráveis disponíveis nas lojas físicas (Niranjanamurthy, Kavyashree, Jagannath, \& Chahar, 2013). Logo, o consumidor teria que se deslocar de loja física em loja física para comparar esses preços e, ao adotar esse tipo de CCC, o processo comparativo se torna mais ágil. Assim,

$\mathbf{H}_{2}$ : O aumento da frequência da comparação de produtos e preços, um tipo de CCC, aumenta a frequência de compras online e offline, com maior intensidade para bens duráveis do que para bens não duráveis.

Já o comportamento de canal cruzado, busca de informação simultânea, deve incentivar as compras online. Isso se deve ao fato de que, como há maior disponibilidade de produtos no mundo virtual (Niranjanamurthy et al., 2013), as informações são mais vastas e completas do que no ponto de 
venda físico e, ao procurar essas informações no meio virtual, os consumidores efetuam as compras no canal que tem mais informação. Produtos de compra rotineira (Oliveira-Castro et al., 2005), tais como alimentos, produtos de higiene e limpeza, estão mais propensos a sofrer esse tipo de comportamento pelo consumidor, porque estão mais relacionados à sua saúde cotidiana, sendo estes, assim, mais críticos ao buscar informação. Portanto,

$\mathbf{H}_{3}$ : O aumento da frequência da busca de informação simultânea, um tipo de CCC, aumenta a frequência de compra online com maior intensidade para bens não duráveis do que para bens duráveis.

Por outro lado, as interações do consumidor junto ao varejista ou ao fabricante, numa situação de canal cruzado, geralmente ocorrem devido aos problemas de compras, seja via Serviço de Atendimento ao Consumidor ou devido à divulgação da má reputação da empresa (Ang \& Buttle, 2012). Ademais, se o comportamento de canal cruzado ocorrer após a efetuação da compra em um dos canais (ex: físico) e usa o outro canal (ex: online) apenas para acompanhar o pedido, a compra no outro canal se torna desnecessária porque já ocorreu. As compras de bens não duráveis devem ser mais sensíveis para essas situações devido ao volume que geralmente se compra desses bens em uma mesma ocasião (Porto, Oliveira-Castro, \& Seco-Ferreira, 2011). Se o consumidor estiver desconfiado do fabricante ou do varejista, ele deixa de comprar, em especial no meio online (ele fecha a tela do possível carrinho de compra virtual). Dessa maneira,

$\mathbf{H}_{4}$ : $\mathrm{O}$ aumento da frequência da interação consumidor com fabricante/varejista, um tipo de CCC, reduz a frequência de compra online, com maior intensidade para bens não duráveis do que para bens duráveis.

Baseada nas propostas teóricas das relações entre resposta-resposta e a possibilidade do processo de compra ser diferente entre o canal online e o offline, o modelo da pesquisa propõe testar a relação mediação-moderada demonstrada na Figura 1. Nele, as três dimensões do CCC são as variáveis mediadoras entre a adoção de dispositivos móveis com acesso à internet e a frequência de compras nos canais online e offline. Os tipos de bens comprados (bens duráveis versus não duráveis) são moderadores dessas relações.

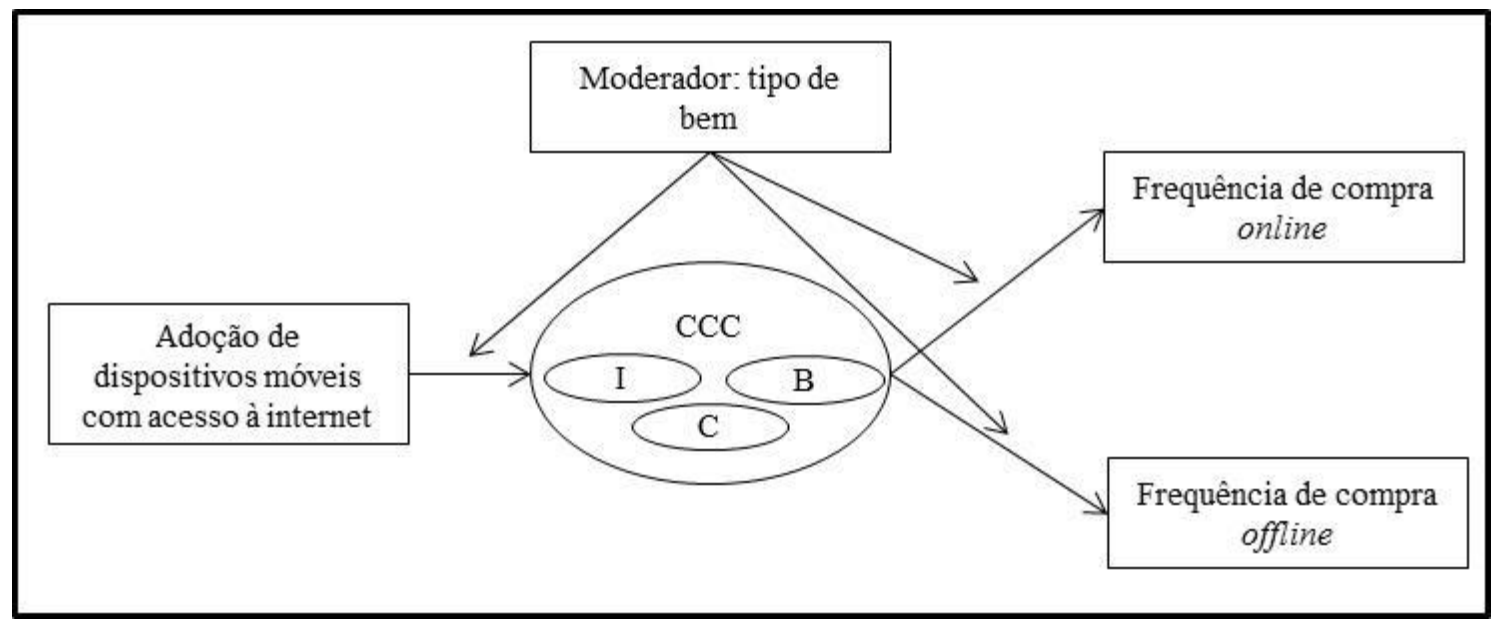

Figura 1. Modelo Teórico - Mediação-moderada do CCC

Legenda: CCC - Comportamento em canais cruzados; I - dimensão do CCC de Interação com o varejista/fabricante; B dimensão do CCC de Busca de informação simultânea; C - dimensão do CCC de Comparação de produtos e preços. 


\section{Método}

Foi operacionalizado um quase experimento de corte transversal com dois grupos em delineamento fatorial (Cozby \& Bates, 2015). Os grupos foram compostos por simulação contextual: o primeiro grupo (239 respondentes) foi composto por indivíduos que receberam a seguinte instrução para responder: "Imagine que você é um consumidor que pretende comprar um bem não durável (ex: alimentos, bebidas, produtos de higiene pessoal, produtos de limpeza) e, nessa ocasião, você utiliza a Internet e/ou uma loja física para realizar a compra. Assinale a alternativa que corresponde ao seu comportamento referente ao processo de compra desse bem não durável, utilizando os canais online e offline".

O segundo grupo (212 respondentes) foi composto por indivíduos que receberam a mensagem: "Imagine que você é um consumidor que pretende comprar um bem durável (ex: eletrodomésticos, eletroeletrônicos, produtos de áudio/vídeo, computadores ou celulares) e, nessa ocasião, você utiliza a Internet e/ou uma loja física para realizar uma compra. Assinale a alternativa que corresponde ao seu comportamento referente ao processo de compra desse bem durável utilizando os canais online e offline".

Fizeram-se necessárias essas duas amostras para que houvesse um efeito mais fidedigno da manipulação experimental em um delineamento fatorial $(2 \times 2)$, condição de compra de dois tipos de bens diferentes. Assim, os respondentes teriam que se colocar na situação de compra ilustrada, para depois responder as questões do questionário. O grupo que o consumidor era alocado foi designado, de forma aleatória, pelo sistema de pesquisa online - cada respondente que respondesse era direcionado para um grupo diferente. Após isso, houve a junção da amostra, compondo o total de 451 consumidores que participaram da pesquisa em sete cidades brasileiras: Belo Horizonte, Uberlândia, Brasília, Goiânia, Anápolis, Ribeirão Preto e São Paulo.

O poder amostral para Análise Fatorial Confirmatória obtido na análise multigrupo (MGA) http://www.quantpsy.org/rmsea/rmsea.htm - com 88 graus de liberdade, alpha de 0,01, RMSEA de hipótese nula na ordem de 0,08 e de hipótese alternativa na ordem de 0,05 foi igual a 99,85\%. O resultado foi bom o suficiente para reduzir as chances de ocorrência do Erro Tipo 2, falso negativo.

Ao todo, 52,8 \% da amostra foi composta pelo sexo feminino, e 47,2\%, do sexo masculino. Cerca de $75,0 \%$ dos respondentes declararam estar na faixa etária de 25 a 59 anos, e, mais da metade, com $53,5 \%$, declararam estar na faixa de renda entre 1 e 5 salários mínimos. A frequência média de compra de bens não duráveis no meio online foi na ordem de 1,42 (Desvio Padrão $=1,18$ ) e no meio offline foi de 2,67 (Desvio Padrão = 1,29). Já a frequência média de compra de bens duráveis no meio online foi da ordem de 3,31 (Desvio Padrão = 1,25) e, no meio offline, foi de 2,33 (Desvio Padrão = 1,57).

Um número significativo de respondentes (42,6\%) declarou ter posse de dois dispositivos móveis, em sua maioria os dispositivos laptops e smartphones, e $33 \%$ declararam a posse de três dispositivos móveis, laptops, smartphones e tablets. Esse resultado é relevante, uma vez que 75,6\% dos respondentes declararam ter posse de dois ou mais dispositivos móveis com acesso à Internet para a possibilidade de realização de compras online, se necessário.

A pesquisa fez uso da escala de Comportamento em Canais Cruzados (Cross Channel Behavior) elaborada e validada por Análise Fatorial Confirmatória (AFC) por Porto e Okada (2018). Nela há três constructos que representam o CCCC: (a) Comparação de produtos e preços (Média =3,00; Desvio Padrão = 0,81); (b) Busca de informação simultânea (Média = 3,33; Desvio Padrão =0,92); e (c) Interação com o varejista/fabricante (Média 3,64=; Desvio Padrão =0,88). A operacionalização e a redação dos itens da escala, bem como das demais variáveis da pesquisa, podem ser vistas na Tabela 1 . 
Tabela 1

Definição Operacional das Variáveis e Codificação

\begin{tabular}{|c|c|}
\hline Variáveis & Definição operacional e codificação \\
\hline \multicolumn{2}{|l|}{ Variável Moderadora } \\
\hline \multirow[t]{2}{*}{ Tipos de bens } & Grupo $0=$ Bens Duráveis \\
\hline & Grupo 1 = Bens Não Duráveis \\
\hline \multicolumn{2}{|l|}{ Variável antecedente } \\
\hline \multirow{3}{*}{$\begin{array}{l}\text { Adoção de dispositivos } \\
\text { móveis com acesso à } \\
\text { internet }\end{array}$} & $1=1$ dispositivo móvel com acesso à internet \\
\hline & $2=2$ dispositivos móveis com acesso à internet \\
\hline & $3=3$ ou mais dispositivos móveis com acesso à internet \\
\hline \multicolumn{2}{|c|}{ Variável Dependente e Mediadora } \\
\hline $\mathrm{CCCC}$ & CCC Busca de informação simultânea (3 itens): \\
\hline \multirow{3}{*}{$\begin{array}{l}\text { Escala de } 5 \text { pontos de } \\
\text { frequência (nunca- } \\
\text { sempre) }\end{array}$} & $\begin{array}{l}\text { CCC1 - Ao mesmo tempo em que estou comprando na loja física, estou online } \\
\text { (com meu celular) pesquisando o mesmo produto na Internet. }\end{array}$ \\
\hline & $\begin{array}{l}\mathrm{CCC} 2 \text { - Vejo uma oferta promocional em uma loja física e, ao mesmo tempo, } \\
\text { busco por preços menores na Internet (pelo celular/tablet). }\end{array}$ \\
\hline & $\begin{array}{l}\text { CC3 - Enquanto estou na loja física, utilizo aplicativos para celulares e/ou tablets } \\
\text { com a finalidade de obter informações adicionais sobre os produtos }\end{array}$ \\
\hline
\end{tabular}

CCC Comparação de produtos e preços ( 3 itens):

CCC4 - Uso meu smartphone, tablet ou laptop para comparar preços de produtos antes de comprar na loja física.

CCC5 - Quando estou em uma loja física para comprar um produto, uso meu smartphone ou tablet para comparar os preços do mesmo produto em outras lojas. CC6 - Utilizo aplicativos de celulares e/ou tablets para comparar qual a loja física fica mais próxima para efetuar a compra de produtos.

CCC Interação com o varejista/fabricante ( 3 itens):

CCC7 - Antes de realizar a compra na loja física, busco na Internet informações sobre a reputação do fabricante/ vendedor.

CCC8 - Utilizo a Internet para emitir sugestões e/ou reclamações (serviço de atendimento ao consumidor [SAC]) de uma compra realizada na loja física. CCC9 - Após realizar o pagamento de um produto na loja física, acompanho e rastreio meu pedido pela internet em dispositivos móveis (celular, tablet, laptop).

\section{Variáveis dependentes consequentes}

Frequência de compras $1=$ Menos de 1 vez por semana/ano online* $^{*}$

$2=$ de 1 a 2 vezes por semana/ano

$3=$ de 3 a 4 vezes por semana/ano

$4=5$ a 6 vezes por semana/ano

$5=7$ vezes ou mais por semana/ano

Frequência de compras $1=$ Menos de 1 vez por semana/ano offline*

$2=$ de 1 a 2 vezes por semana/ano

$3=$ de 3 a 4 vezes por semana/ano

$4=5$ a 6 vezes por semana/ano

$5=7$ vezes ou mais por semana/ano

Nota. * A frequência semanal de compras se refere à compra de bens não duráveis. BND =1 = menos de 1 vez por semana; 5 $=$ sete vezes por semana; * A frequência anual de compras se refere à compra de um bem durável. $\mathrm{BD}=1=$ menos de 1 vez por ano; 5 = mais de 7 vezes por ano. 
Os testes de validade convergente indicaram que todos os constructos confirmados pela AFC tiveram a variância média extraída (AVE) superior a 0,50 (variando entre 0,52 para comparação de produtos e preços a 0,70 para busca de informação simultânea), que indica que os carregamentos dos constructos são significativos e que há evidências de que as variáveis observáveis têm validade convergente (Hair, Gabriel, \& Patel, 2014).

Os resultados obtidos da Confiabilidade Composta (CC) mostraram que todas as variáveis que permaneceram no modelo de medição de cada constructo tiveram confiabilidade superior a 0,70 , sendo que a confiabilidade mínima resultou em 0,80 e, a máxima, em 0,81. A análise da validade discriminante ocorreu por meio do critério de Fornell e Larcker e evidenciou que o valor da Variância Média Extraída - AVE dos constructos era superior ao valor das correlações elevadas ao quadrado.

Os questionários foram aplicados por um período de 10 semanas, de 31 de maio a 9 de agosto de 2015. Para a Modelagem de Equações Estruturais (Structural Equation Modeling [SEM]), utilizou-se o software AMOS. A mediação foi analisada por meio do modelo estrutural de caminhos e a moderação foi analisada por meio da comparação multigrupos, com o Teste do Escore Z. Elaborou-se um modelo com cargas fatoriais restritas e iguais entre os 2 grupos. Os valores das estimativas não padronizadas, tanto para bens duráveis quanto para bens não duráveis, foram inseridos no modelo por meio das comparações de parâmetros pairwise. A partir de então, calculou-se o Z score da diferença entre os grupos.

Utilizou-se o método de estimação da Máxima Verossimilhança (Maximum-Likelihood Estimation [MLE]). Os dados não apresentaram problemas de multicolinearidade (VIF < 2 para qualquer uma das relações feitas), mas outliers foram detectados e excluídos para a análise final. Assim, na análise final, os dados apresentaram distribuição normal multivariada pelo teste Mardia (C.R. Kurtosis =1,16 para bens duráveis e C.R. Kurtosis = 1,89 para bens não duráveis). Os erros de medição entre as frequências de compras online e offline estavam correlacionados, mas não são explicados nos modelos. $\mathrm{O}$ mesmo pode ser dito sobre os três constructos do CCC entre eles. Por isso, no modelo, essas variáveis covariaram.

\section{Resultados}

Foram realizados dois modelos concorrentes. O primeiro contém apenas a relação de mediação entre a variável antecedente (adoção de dispositivos móveis com acesso à internet), as mediadoras (os três constructos do CCC) e as dependentes finais (as frequências de compra online e offline). O segundo contém as mesmas relações mediadoras, porém agora moderadas pelo tipo de bem (duráveis e não duráveis). Os índices de ajuste absoluto e parcimonioso de ambos os modelos atenderam as recomendações para adequação dos modelos que foram considerados aceitáveis (Hair, Black, Babin, \& Anderson, 2010), como demonstra a Tabela 2. Mas o Modelo 2 (mediação-moderada) apresentou-se um pouco melhor nos critérios de RMSEA e de CFI. 
Tabela 2

Medidas de Ajuste Geral dos Modelos da Pesquisa

\begin{tabular}{cccc}
\hline $\begin{array}{c}\text { Medidas de ajuste } \\
\text { absoluto/parcimonioso }\end{array}$ & Valor aceitável & $\begin{array}{c}\text { Modelo 1 (mediação } \\
\text { simples) }\end{array}$ & $\begin{array}{c}\text { Modelo 2 (mediação- } \\
\text { moderada) }\end{array}$ \\
\hline Qui-quadrado $\left(\chi^{2}\right)^{\mathrm{a}}$ & $\begin{array}{c}\text { Valores menores resultam } \\
\text { em maiores níveis de } \\
\text { significância }\end{array}$ & $\begin{array}{c}186,94 \\
(\mathrm{p} \leq 0,01)\end{array}$ & $173,82(\mathrm{p} \leq 0,01)$ \\
\hline $\begin{array}{c}\text { Índice de qualidade do } \\
\text { ajuste (GFI) }\end{array}$ & Acima de 0,90 & 0,94 & 0,94 \\
\hline $\begin{array}{c}\text { Raiz do resíduo quadrático } \\
\text { médio padronizado } \\
\text { (SMRS) }\end{array}$ & Valores inferiores a 0,10 & 0,05 & 0,05 \\
\hline $\begin{array}{c}\text { Raiz do erro quadrático } \\
\text { médio de aproximação } \\
\text { (RMSEA) }\end{array}$ & $\begin{array}{c}\text { Valores inferiores a 0,08 } \\
\text { Índice de ajuste } \\
\text { comparativo (CFI) }\end{array}$ & 0,06 & 0,92 \\
\hline $\begin{array}{c}\text { Qui-quadrado ponderado } \\
\text { Acima de 0,90 }\end{array}$ & $\begin{array}{c}\text { Valores inferiores a 1 } \\
\text { indicam um ajuste pobre; } \\
\text { valores acima de 5 } \\
\text { indicam necessidade de } \\
\text { ajuste. }\end{array}$ & 0,91 & 1,98 \\
\hline & 4,24 & \\
\hline
\end{tabular}

Nota. Fonte: Dados da pesquisa.

${ }^{a}$ Qui-quadrado: valor obtido na análise multigrupo.

Como o foco da análise é demonstrar a relação de mediação-moderada e testar as hipóteses de 1 a 4, os resultados que seguem são referentes apenas a esse modelo (Modelo 2). A Tabela 3 ilustra as estimativas não padronizadas e padronizadas, bem como os erros padronizados grau de significância e o Teste do Escore Z da mediação-moderada.

Inicialmente, percebe-se que a adoção de dispositivos móveis com acesso à internet foi preditor positivo e significativo de todos os constructos do CCC em ambos os contextos dos tipos de bens, com exceção para busca de informação simultânea de bens duráveis (não significativo). Porém, a força da relação dos constructos do CCC para as duas variáveis de frequência de compra depende do nível da variável moderadora. As relações foram mais fortes para os bens não duráveis do que para bens duráveis, o que corrobora $\mathrm{H} 1-\mathrm{H}_{1 \mathrm{a}}$ e $\mathrm{H}_{1 \mathrm{c}}$. Já para $\mathrm{H}_{1 \mathrm{~b}}$, a relação de moderação não foi confirmada. Isso porque, para ambos os tipos de bens, a relação positiva da adoção de dispositivos móveis com acesso à internet sobre a comparação de produtos e preços apresentou-se com o mesmo nível de força. 
Tabela 3 Estimativas Padronizadas de Bens Duráveis e Bens não Duráveis do Modelo 2 (Mediação-
moderada)

\begin{tabular}{|c|c|c|c|c|c|c|c|c|c|}
\hline \multirow{2}{*}{$\begin{array}{l}\text { Variável } \\
\text { dependente }\end{array}$} & \multirow{2}{*}{\multicolumn{2}{|c|}{$\begin{array}{l}\text { Variável } \\
\text { independente }\end{array}$}} & \multicolumn{3}{|c|}{ Moderador: b. dur. } & \multicolumn{3}{|c|}{ Moderador: b. não dur. } & \multirow[t]{2}{*}{$z$-score } \\
\hline & & & $\begin{array}{l}\text { Estim. } \\
\text { Não Pad. }\end{array}$ & $\begin{array}{l}\text { Erro } \\
\text { Pad. }\end{array}$ & $\begin{array}{l}\text { Estim. } \\
\text { Pad. }\end{array}$ & $\begin{array}{l}\text { Estim. } \\
\text { Não Pad. }\end{array}$ & $\begin{array}{l}\text { Erro } \\
\text { Pad. }\end{array}$ & $\begin{array}{l}\text { Estim. } \\
\text { Pad. }\end{array}$ & \\
\hline $\begin{array}{l}\text { CCCC -Busca de } \\
\text { informação } \\
\text { simultânea (B) }\end{array}$ & & $\begin{array}{l}\text { Adoção de } \\
\text { dispositivos } \\
\text { móveis com } \\
\text { acesso à internet }\end{array}$ & $-0,06$ & 0,1 & $-0,05$ & $0,45^{* * *}$ & 0,1 & 0,29 & $3,63^{* * * *}$ \\
\hline $\begin{array}{l}\text { CCCC - } \\
\text { Comparação de } \\
\text { produtos/preços } \\
\text { (C) }\end{array}$ & & $\begin{array}{l}\text { Adoção de } \\
\text { dispositivos } \\
\text { móveis com } \\
\text { acesso à internet }\end{array}$ & $0,14 * * *$ & 0,1 & 0,24 & $0,14 * * *$ & 0,1 & 0,30 & 0,02 \\
\hline $\begin{array}{l}\text { CCCC = Interação } \\
\text { com } \\
\text { varejista/fabricante } \\
\text { (I) }\end{array}$ & $\leftarrow$ & $\begin{array}{l}\text { Adoção de } \\
\text { dispositivos } \\
\text { móveis com } \\
\text { acesso à internet }\end{array}$ & $0,22 * *$ & 0,1 & 0,26 & $0,69^{* * *}$ & 0,1 & 0,58 & $4,04 * * *$ \\
\hline $\begin{array}{l}\text { Frequência de } \\
\text { compra online }\end{array}$ & & $\begin{array}{l}\text { CCCC - } \\
\text { Comparação de } \\
\text { produtos/preços } \\
\text { (C) }\end{array}$ & $1,82 * *$ & 0,7 & 0,61 & $-0,31$ & 0,4 & $-0,10$ & $-2,58 * * *$ \\
\hline $\begin{array}{l}\text { Frequência de } \\
\text { compra offline }\end{array}$ & & $\begin{array}{l}\text { CCCC - } \\
\text { Comparação de } \\
\text { produtos/preços } \\
\text { (C) }\end{array}$ & $1,96 * *$ & 0,9 & 0,53 & 0,29 & 0,4 & 0,08 & $-1,72^{* * * *}$ \\
\hline $\begin{array}{l}\text { Frequência de } \\
\text { compra online }\end{array}$ & & $\begin{array}{l}\text { CCCC -Busca de } \\
\text { informação } \\
\text { simultânea (B) }\end{array}$ & $-0,37$ & 0,3 & $-0,24$ & $0,55^{*}$ & 0,1 & 0,57 & $2,82 * * *$ \\
\hline $\begin{array}{l}\text { Frequência de } \\
\text { compra offline }\end{array}$ & & $\begin{array}{l}\text { CCCC -Busca de } \\
\text { informação } \\
\text { simultânea (B) }\end{array}$ & $-0,42$ & 0,4 & $-0,21$ & 0,20 & 0,1 & 0,19 & 1,57 \\
\hline $\begin{array}{l}\text { Frequência de } \\
\text { compra online }\end{array}$ & $\leftarrow$ & $\begin{array}{l}\text { CCCC = Interação } \\
\text { com } \\
\text { varejista/fabricante } \\
\text { (I) }\end{array}$ & $-0,19$ & 0,3 & $-0,09$ & $-0,34 * *$ & 0,1 & $-0,28$ & $-0,51$ \\
\hline $\begin{array}{l}\text { Frequência de } \\
\text { compra offline }\end{array}$ & $\leftarrow$ & $\begin{array}{l}\mathrm{CCCC}=\text { Interação } \\
\text { com } \\
\text { varejista/fabricante } \\
\text { (I) }\end{array}$ & $-0,55$ & 0,3 & $-0,20$ & 0,19 & 0,2 & 0,14 & 1,97 \\
\hline
\end{tabular}

Nota. Fonte: Dados da pesquisa.

$* * *$ p-valor $\leq 0,01 ; * *$ p-valor $\leq 0,05$.

Ainda na Tabela 3, ao analisar relações consequentes do CCC, apenas a dimensão comparação de produtos e preços foi preditora, positiva de ambas as frequências de compra, com maior força para bens duráveis, o que corrobora $\mathrm{H}_{2}$. A busca de informação simultânea foi preditora positiva da frequência de compra online para bens não duráveis, diferente do que ocorre para bens duráveis. Logo, $\mathrm{H}_{3}$ também é corroborada.

A interação com varejista/fabricante foi preditora negativa da frequência de compra online, porém apenas para bens não duráveis, de forma significativa. A moderação também não se apresentou 
estatisticamente significativa. Dessa forma, $\mathrm{H}_{4}$ não se confirmou apesar das relações demonstrarem serem negativas, conforme seria esperado $\mathrm{em} \mathrm{H}_{4}$.

Em resumo, o score $Z$ acusa que existe moderação de cinco das nove relações testadas no Modelo 2. Existe tanto moderação entre a adoção de dispositivos móveis com acesso à internet e as dimensões do CCC quanto também destes com ambas as frequências. As Figuras 2 (para frequência de compra online) e 3 (para frequência de compra offline) ilustram, por meio das estimativas padronizadas, as relações de mediação-moderada encontradas. Apesar de os dois modelos rodados (ilustrados nessas figuras) apresentarem as variáveis de frequência de compra (online e offline) endógenas, preferiu-se demonstrar o efeito nessas variáveis de forma separada para facilitar a visualização dos resultados da mediação-moderada.

Na Figura 2, observa-se que, para o bem durável, apenas a dimensão comparada de produtos e preços é mediadora positiva da relação entre adoção de dispositivos móveis com acesso à internet e a frequência de compras online. Já para os bens não duráveis, a busca de informação simultânea é mediadora positiva da frequência de compra online enquanto que a interação com varejista/fabricante é mediadora negativa. A comparação de produtos e preços para os bens não duráveis não é mediadora.

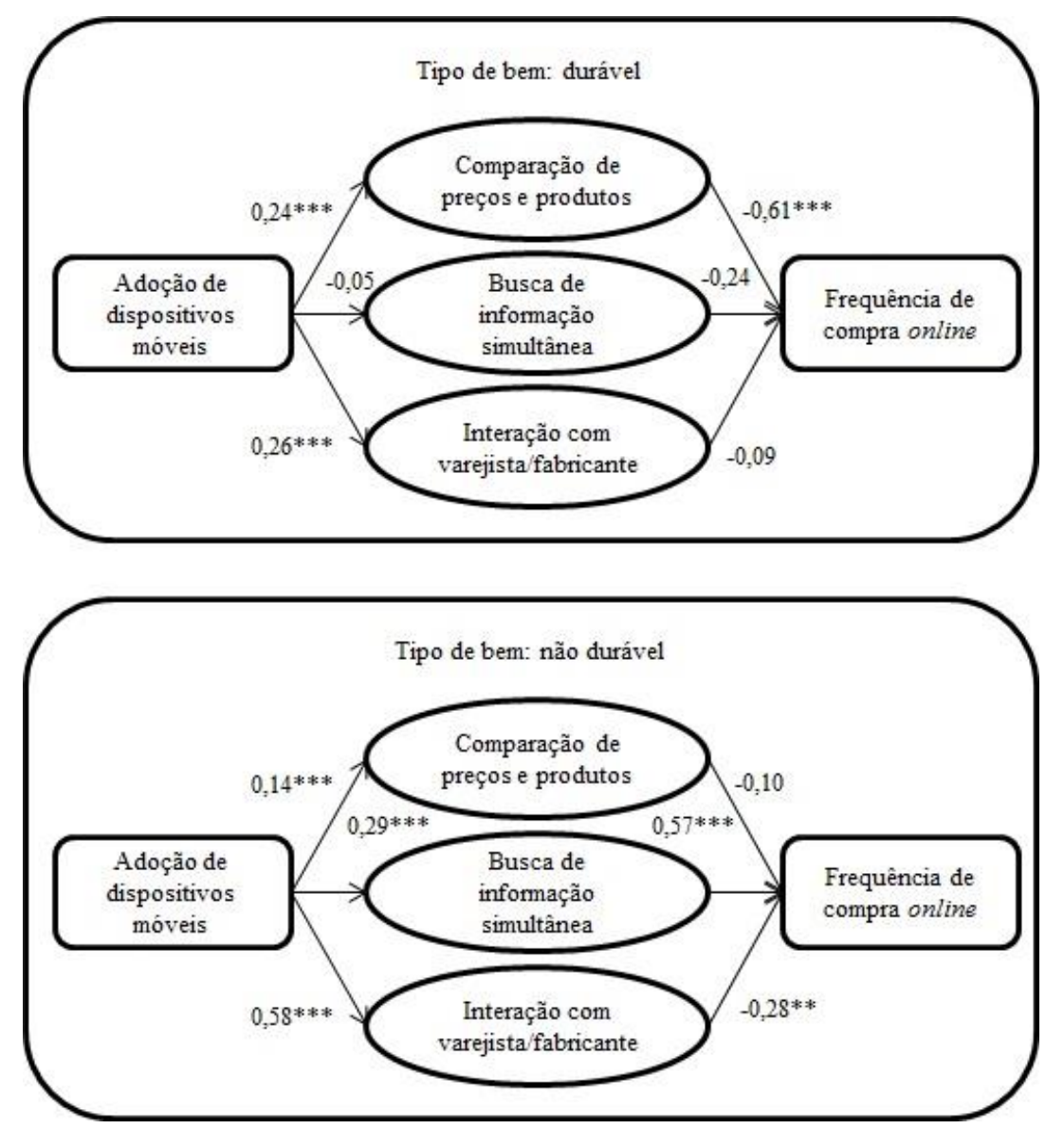

Figura 2. Efeito Padronizado do Modelo de Mediação-moderada sobre a Frequência de Compra Online para Bens Duráveis e Não Duráveis

Bens não duráveis: $\mathrm{R}^{2}=33,3 \%$ (CCCC - I), $\mathrm{R}^{2}=8,5 \%(\mathrm{CCCC}-\mathrm{B}), \mathrm{R}^{2}=8,9 \%\left(\mathrm{CCCC}-\mathrm{C}\right.$ ), $\mathrm{R}^{2}=17,8 \%$ (frequência de compra online). Bens duráveis: $\mathrm{R}^{2}=6,8 \%\left(\right.$ CCCC - I), $\mathrm{R}^{2}=0,3 \%(\mathrm{CCCC}-\mathrm{B}), \mathrm{R}^{2}=5,5 \%(\mathrm{CCCC}-\mathrm{C}), \mathrm{R}^{2}=17,7 \%$ (frequência de compra online). Fonte: Dados da pesquisa. $* * *$ p-valor $\leq 0,01 ; * *$ p-valor $\leq 0,05$.

As variâncias explicadas são mostradas nas Figura 2 e 3. Elas são baixas como um todo, mas não são tão relevantes para o propósito dessa pesquisa, já que existem outras influenciadoras das frequências de compra e das dimensões do CCC além das variáveis aqui investigadas. 


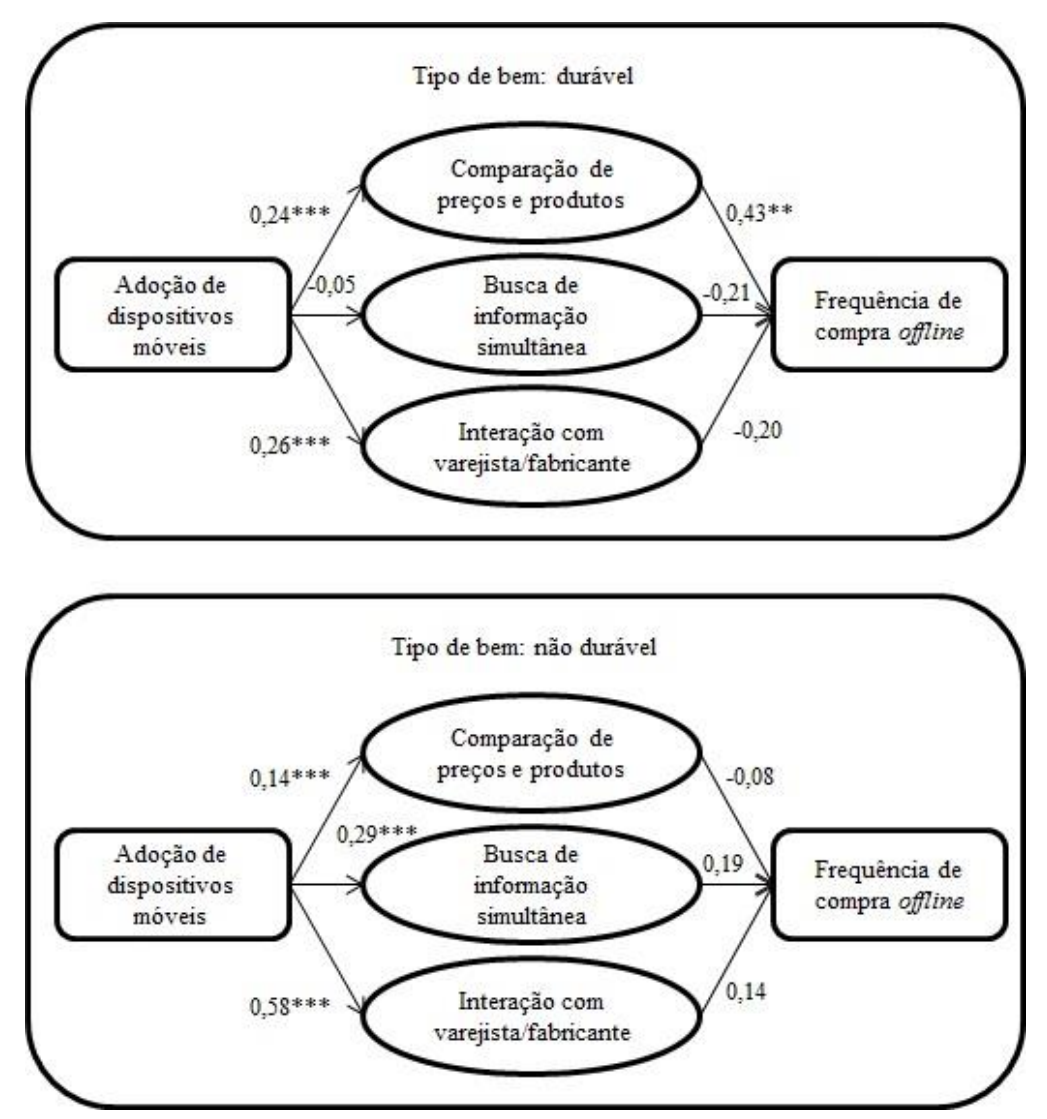

Figura 3. Efeito Padronizado do Modelo de Mediação-moderada sobre a Frequência de Compra Offline para Bens Duráveis e Não Duráveis

Bens não duráveis: $\mathrm{R}^{2}=33,3 \%$ (CCCC - I), $\mathrm{R}^{2}=8,5 \%(\mathrm{CCCC}-\mathrm{B}), \mathrm{R}^{2}=8,9 \%(\mathrm{CCCC}-\mathrm{C}), \mathrm{R}^{2}=12,4 \%$ (frequência de compra offline). Bens duráveis: $\mathrm{R}^{2}=6,8 \%$ (CCCC - I), $\mathrm{R}^{2}=0,3 \%$ (CCCC - B), $\mathrm{R}^{2}=5,5 \%$ (CCCC - C), $\mathrm{R}^{2}=12,0 \%$ (frequência de compra online). Fonte: Dados da pesquisa.

*** p-valor $\leq 0,01 ; * *$-valor $\leq 0,05$.

Como resultado extra, a Tabela 4 ilustra a influência total padronizada (efeitos direto e indireto) da adoção de dispositivos móveis com acesso à internet na frequência de compras online e offline. Percebe-se que a influência é baixa em qualquer condição, mas são aproximadamente oposta a depender da variável moderadora (bens não duráveis versus duráveis). A adoção de dispositivos móveis com acesso à internet exerce influência um pouco maior para a frequência de compra offline quando o CCC se refere aos bens não duráveis enquanto a adoção de dispositivos móveis com acesso à internet exerce influência um pouco maior para a frequência de compra online, quando o CCC se refere aos bens duráveis.

Tabela 4

Estimativas Padronizadas Totais da Influência da Adoção de Dispositivos Móveis com Acesso à Internet na Frequência de Compra de Bens Duráveis e Bens Não Duráveis

\begin{tabular}{llcc}
\hline Variável dependente & Variável antecedente & \multicolumn{2}{c}{ Efeito total padronizado } \\
\cline { 3 - 4 } Frequência de compra offline & $\leftarrow \begin{array}{l}\text { Adoção de dispositivos móveis } \\
\text { com acesso à internet }\end{array}$ & $0,16^{* *}$ & $0,08^{* *}$ \\
Frequência de compra online & $\leftarrow \begin{array}{l}\text { Adoção de dispositivos móveis } \\
\text { com acesso à internet }\end{array}$ & $-0,02$ & $0,13^{* *}$ \\
\hline
\end{tabular}

Nota. Fonte: Dados da pesquisa.

$* * *$ p-valor $\leq 0,01 ; * *$ p-valor $\leq 0,05$. 


\section{Discussão}

O resultado revela que os comportamentos dos consumidores de canais cruzados mediam a relação entre a adoção de dispositivos móveis com acesso à internet e a frequência de compra online e offline, porém moderada pelos bens duráveis e não duráveis. A pesquisa corroborou $\mathrm{H}_{1 \mathrm{a}}, \mathrm{H}_{1 \mathrm{c}}, \mathrm{H}_{2}$ e $\mathrm{H}_{3}$. $\mathrm{O}$ modelo mediador-moderador apresentou-se melhor em indicadores parcimoniosos e manteve os indicadores de ajustes a níveis muito bons. Dessa forma, comprova-se que uma das consequências comportamentais da adoção de dispositivos móveis com acesso à internet (Sanakulov \& Karjaluoto, 2015) é o aumento da frequência do Comportamento em Canais Cruzados, e uma das consequências desses últimos é o aumento ou decréscimo da frequência de compra (Nadarajah \& Kotz, 2009), a depender dos tipos de bens.

Isso corrobora as relações dos estudos sobre comportamentos precorrentes e correntes da área comportamental (Pohl \& Oliveira-Castro, 2008; Skinner, 2013). Devido à força de influência da adoção de dispositivos móveis com acesso à internet (Wang et al., 2015) no CCC, o argumento de que essa adoção é um precorrente requerido pela contingência comportamental torna-se mais plausível. Em outras palavras, a maior disponibilidade de aparelhos móveis com acesso à Internet, quando em uso em ambientes de compra pelo consumidor, intensifica e possibilita-lhe necessariamente a ocorrência do CCC. Ele adquire propriedades de estímulo discriminativo, sinalizando que, com sua presença no ambiente de compra, o consumidor pode realizar determinados comportamentos e, com isso, comprar os produtos com fins de usufruí-los (Foxall, 2015). Isso porque o CCC é um tipo de comportamento aprendido (Pierce \& Cheney, 2013) e necessita de tecnologia com acesso wireless para ocorrer.

Esse achado ocorre tanto para compras de bens não duráveis quanto para bens duráveis, sendo que, para esses últimos, apenas a dimensão busca de informação simultânea não é preditora do CCC. Isso se deve porque os consumidores, que planejam suas compras, quando pretendem comprar bens duráveis, já se deslocam ao ponto de venda com informação acerca dos produtos (Xia \& Monroe, 2005). Logo, não julgam necessário consultar informações extras via dispositivos móveis simultaneamente.

Além disso, o efeito da adoção de dispositivos móveis com acesso à internet sobre as dimensões do CCC é mais forte para bens não duráveis do que para bens duráveis, conforme ilustra a análise de moderação. O uso de dispositivos móveis tem propiciado a eficiência do processo de compra principalmente aplicado aos bens não duráveis devido à rotina que se estabelece as compras desses bens (Wang et al., 2015) e o esforço depreendido (Jiang et al., 2013). Geralmente, supermercados, mercearias ou farmácias são os pontos de venda que se compram esse tipo de bem (Dunne et al., 2013). O porte de dispositivos móveis pode ser mais incidente nesses locais, porque consumidores estão mais presentes neles do que em lojas de eletrodomésticos ou eletroeletrônicos. Em termos gerais, consumidores participam de processos de compra com maior frequência de comida ou bebida do que de eletrodoméstico ou de eletroeletrônicos. Logo, a efetividade dos dispositivos móveis na geração de um novo repertório comportamental que torne ágil o processo de compra é mais provável para essas compras. Atenta-se apenas que $\mathrm{H}_{1 b}$ não foi corroborada porque, para ambos os tipos de bens, a relação tem a mesma intensidade.

No entanto, a adoção de dispositivos móveis com acesso à internet não é a causa única do CCC. As variâncias explicadas baixas oferecem indício disso. Por um instante, é necessário também saber operar o dispositivo móvel, ter tempo para usá-lo, saber procurar na internet a informação que se pretende obter, a empresa varejista precisa possibilitar o uso de dispositivos móveis com internet em seus ambientes, o consumidor necessita ter dinheiro para aquisição de dispositivos móveis e produtos, e tantas outras possíveis causas. Ou seja, demanda-se uma série de tarefas de aprendizagem (Pierce \& Cheney, 2013) e de condições indutoras (ou de controle de estímulos - Skinner, 2013) para que haja ocorrência do CCC, mas que não foi foco da presente pesquisa.

A pesquisa também demonstrou que a adoção de tecnologias móveis com acesso à internet gera efeito total, mas de baixa influência, na frequência de compra (Nadarajah \& Kotz, 2009). Assim, essa pesquisa vai ao encontro de pesquisas que demonstram que os dispositivos móveis têm sido responsáveis 
por um pequeno aumento nas vendas do varejo offline e online (Wang et al., 2015). No entanto, esse aumento na frequência é mais visível via o novo repertório comportamental vindo do CCC cujos consumidores vêm adotando nos últimos anos, além da adoção propriamente dita dos dispositivos móveis.

De forma complementar, o aumento da frequência de execução de cada dimensão do CCC influencia a frequência de compra, mas essa influência varia bastante a depender do tipo de bem comprado e também se a compra ocorre online ou offline. Dessa maneira, novamente mais uma evidência das relações dos estudos sobre comportamentos precorrentes e correntes da área comportamental (Pohl \& Oliveira-Castro, 2008; Skinner, 2013). Mas, dessa vez, nessas relações, o CCC é um precorrente não requerido pela contingência comportamental. Sua função é de treino em um processo de aprendizagem (ou de etapas dos processos de resolução de problema - Aggio et al., 2016). Para consumidores inexperientes ou não tão experientes, o consumidor pode inserir esse conjunto de comportamento em seu repertório para aumentar as chances de fazer uma boa compra. Geralmente, isso ocorre por meio da melhoria da eficiência de seu próprio processo de compra (ex: poupar mais dinheiro, comprar produtos que ofereçam mais benefícios ou de melhor qualidade, etc). Ressalta-se que para aumentar ou decair a frequência da compra, o CCC, em qualquer uma de suas dimensões, não é necessário, mas auxiliar. Assim, se o consumidor abarcá-lo em seu repertório comportamental ele passa a auxiliá-lo no processo de compra.

No entanto, os consumidores experientes, com a compra de um produto (Pohl \& Oliveira-Castro, 2008), podem eliminar esse conjunto de CCC porque ele não é necessário se, por exemplo, esse consumidor já tem informação suficiente acerca das funções dos produtos (e não precisaria buscar mais informação), ou mesmo se já sabe dos preços dele em outras lojas (não precisaria mais comparar) ou mesmo se já interagiu com o varejista/fabricante sobre esse produto (não precisaria interagir).

Para as compras de bens duráveis, apenas a dimensão de comparação de produtos e preços é preditora da frequência de compra tanto online quanto offline. Dessa forma, a inserção desse novo comportamento do processo de compra parece tornar mais eficiente a comparação de preços desses produtos. Por um instante, lojas de eletrodomésticos e de produtos audiovisuais geralmente não oferecem muita variedade (sortimento de marcas e submarcas) quanto os supermercados ou hipermercados oferecem. Além disso, os preços desses produtos são mais caros do que os bens não duráveis, em termos gerais. Logo, a comparação de produtos e preços proporciona a eficiência do processo de compra ao permitir não pagar tão caro pelo mesmo produto em lojas físicas similares ou no meio online. Ou seja, permite ao consumidor poupar mais dinheiro, tornando mais eficiente adquirir o mesmo produto com menos recurso financeiro.

Em compensação, para as compras de bens não duráveis, a dimensão de comparação de produtos e preços não foi preditora para nenhuma frequência de compra. Mesmo via dispositivos móveis pode não parecer vantajoso ao consumidor. Isso se deve ao menor valor dessas mercadorias e ao custo temporal de ter que comparar preços (Dunne et al., 2013). O esforço de poupar dinheiro quando os itens não são tão caros parece não importar ao consumidor.

Entretanto, o aumento da frequência de busca de informação simultânea aumenta a frequência de compra online para as compras de bens não duráveis. Isso demonstra que os consumidores não julgam as informações disponibilizadas acerca dos produtos pelos fabricantes e varejistas nos pontos de venda suficientes para aumento da frequência da compra (Xia \& Monroe, 2005). Essa situação os leva a buscar mais informações online, e essas novas informações são capazes de induzi-los às compras virtuais, mesmo estando em lojas físicas. Ou seja, essa dimensão do CCC permite ao consumidor encontrar produtos não duráveis mais adequados (ou melhores), tornando mais eficiente adquirir um produto melhor pelo preço similar.

Por outro lado, o aumento da frequência da interação com varejistas/fabricantes diminui a frequência de compra online. Isso ocorre porque consumidores que se informam sobre reputação do fabricante ou varejista na internet por meio de seus dispositivos móveis constatam o tipo ou a quantidade de reclamações que eles têm em sítios eletrônicos (ex: Reclame Aqui) ou mesmo via comentários de consumidores ou de influenciadores do processo de compra, como o boca a boca eletrônico (Coelho, 
Venancio, Calazans, \& Silva, 2016). Igualmente, podem ter interagido via Serviço de Atendimento ao Consumidor de forma virtual após ter comprado um produto em loja física. Isso pode inibir a frequência de compra futura pelo cansaço ou estresse dos problemas referentes à baixa qualidade dos produtos ou do serviço logístico. Ou seja, essa dimensão do CCC permite ao consumidor se afastar de situações em que ele pode perder mais, tornando mais eficiente evitar adquirir produtos ou serviços ruins. No entanto, a moderação do tipo de bem não foi confirmada (H4 não foi corroborada). Isso sinaliza, para ambos os bens, a relação esperada é a mesma.

\section{Conclusão}

Os efeitos de mediação-moderada entre as relações propostas foram confirmados na maior parte dos testes, e tais achados trazem implicações gerenciais às empresas e implicações ao bem-estar dos consumidores. As implicações se referem: (a) à adoção de tecnologias móveis com acesso à internet é indutora de aprendizagem (ou de aperfeiçoamento) dos comportamentos do consumidor em canais cruzados, com maior força para compras de bens não duráveis, , por sua vez, alterações na frequência de compras online e offline; (b) à compreensão de que o CCC (busca de informação simultânea, comparação de produtos/preços e de interação com o varejista/fabricante) altera as frequências de compra no canal online - a busca de informação simultânea aumenta a frequência de compra no canal online e as demais dimensões do CCC a reduz; (c) ao CCC, que altera as frequências de compra no canal offline - a comparação de produtos e preços aumenta a frequência de compra no canal offline e as demais dimensões do CCC não geram impacto significativo; e (d) aos efeitos de cada dimensão do CCC nas frequências de compra online e offline, que são diferentes para bens duráveis versus não duráveis.

Para tanto, é necessário que o gestor saiba o conteúdo do CCC. Especificamente, para o varejista/fabricante, a busca de informação simultânea de produtos dos consumidores demonstra a necessidade da empresa em delinear ações de presença digital com otimização de busca orgânica para que informações mais profundas acerca dos produtos sejam encontradas. Por sua vez, a comparação de produtos e preços pelos consumidores sinaliza o estabelecimento de uma política de precificação competitiva para estarem bem ranqueados nos sites de comparação de preços (ex: Buscapé, Bondfaro, entre outros). Em relação à interação do consumidor com o varejista/fabricante, uma ação gerencial prudente diz respeito aos investimentos em melhoria de sua reputação em rankings que avaliam esse propósito, melhoria contínua na entrega de produtos e no serviço de Atendimento ao Consumidor.

Dentre as limitações, destaca-se o procedimento de coleta de dados que foi realizado a partir do relato de comportamento em uma simulação de compra, em vez da observação do comportamento real. Além disso, a pesquisa utilizou a abordagem clássica do tipo de bem comprado em detrimento de uma abordagem mais ampla contemplando o tipo de bem integrado a serviços.

Recomenda-se que estudos futuros possam superar essas limitações e que os mesmos sejam conduzidos de forma longitudinal, com delineamentos experimentais. Eles podem clarear se, de fato, o processo de compra se modifica via aprendizado desse novo repertório comportamental de canais cruzados. Ademais, o efeito desse processo pode não ser apenas na frequência de compra. Logo outras variáveis dependentes podem ser elencadas em futuras pesquisas, tais como geração de excedente do consumidor (poupança de tempo, de dinheiro e de esforço) ou mesmo geração ou perda de excedente às empresas, como aumentos ou decréscimos de suas lucratividades e rentabilidades.

\section{Material Suplementar}

Todos os dados e materiais foram disponibilizados publicamente por meio da plataforma Zenodo e podem ser acessados em: Sionara Okada, \& Rafael Porto. (2018). Comportamento do Consumidor de Canais Cruzados: Efeitos nas Compras Online e Offline [Data set]. Revista de Admininistração Contemporânea. Zenodo. http://doi.org/10.5281/zenodo.1303670 


\section{Contribuições}

$1^{\circ}$ autor: Definição do problema de pesquisa, desenvolvimento das questões de pesquisa, fundamentação teórica, definição dos procedimentos metodológicos, coleta de dados, análise e interpretação dos dados, redação do manuscrito.

$2^{\circ}$ autor: Desenvolvimento das questões de pesquisa, fundamentação teórica, definição dos procedimentos metodológicos, análise estatística, análise e interpretação dos dados, revisão crítica do manuscrito, redação do manuscrito.

\section{Referências}

Aggio, N. M., Postalli, L. M. M., \& Garcia, L. T. (2016). Implicações educacionais da concepção comportamental de pensamento: Ensinar a pensar e a resolver problemas. Revista Perspectivas, 7(1), 48-58. http://dx.doi.org/10.18761/pac.2015.038

Ang, L., \& Buttle, F. (2012). Complaints-handling processes and organisational benefits: An ISO 10002based investigation. Journal of Marketing Management, 28(9/10), 1021-1042. http://dx.doi.org/10.1080/0267257X.2011.615335

Antéblian, B., Filser, M., \& Roederer, C. (2013). Consumption experience in retail environments: A literature review. Recherche et Applications en Marketing (English Edition), 28(3), 82-109. http://dx.doi.org/10.1177/2051570713505471

Avery, J. T., Steenburgh, J., Deighton, J., \& Caravella, M. (2012). Adding bricks to clicks: Predicting the patterns of cross-channel elasticities over time. Journal of Marketing, 76(3), 96-111. http://dx.doi.org/10.1509/jm.09.0081

Campo, K., \& Breugelmans, E. (2015). Buying groceries in brick and click stores: Category allocation decisions and the moderating effect of online buying experience. Journal of Interactive Marketing, 31, 63-78. http://dx.doi.org/10.1016/j.intmar.2015.04.001

Chiu, H. C., Hsieh, Y. C., Roan, J., Tseng, K. J., \& Hsieh, J. K. (2011). The challenge for multichannel services: Cross-channel free-riding behavior. Electronic Commerce Research and Applications, 10(2), 268-277. http://dx.doi.org/10.1016/j.elerap.2010.07.002

Coelho, G. R. B., Venancio, G., Calazans, J. D. H. C., \& Silva, K. L. (2016). Relações de consumo intermediadas por sites de reclamação on line. Veredas - Revista Eletrônica de Ciências, 8(2), 6987.

Cozby, P. C., \& Bates, S. (2015). Methods in behavioral research. New York: McGraw-Hill

Doong, H. S., Wang, H. C., \& Foxall, G. R. (2011). An investigation of consumers' webstore shopping: A view of click-and-mortar company. International Journal of Information Management, 31(3), 210-216. http://dx.doi.org/10.1016/j.ijinfomgt.2010.06.006

Dunne, P. M., Lusch, R. F., \& Carver, J. R. (2013). Retailing. Masson, USA: Cengage Learning.

Foxall, G. R. (2015). Operant behavioral economics. Managerial and Decision Economics, 27(4/5), 215-223. http://dx.doi.org/10.1002/mde.2712

Gensler, S. S. H., Leeflang, P., \& Skiera, B. (2012). Impact of online channel use on customer revenues and costs to serve: Considering product, portfolios and self-selection. International Journal of Research in Marketing, 29(2), 192-201. http://dx.doi.org/10.1016/j.ijresmar.2011.09.004

Gerritsen, B. H., Soilen, K. S., de Visser, P. B., Hoogreef, P. J., Hulst, K., Janssen, M. L., Horselenberg, L., Van Dijk, R.R., \& Consenheim, E. (2014). Social media coming to the mall: A cross-channel 
response. In D. Schaefer (Ed.), Product development in the socio-sphere (pp. 169-235). Switzerland: Springer International Publishing.

Hair, J. F., Black, W. C., Babin, B. J., \& Anderson, R. E. (2010). Multivariate data analysis (7th ed.). New Jersey: Prentice Hall.

Hair, J. F., Gabriel, M. L. D. S., \& Patel, V. K. (2014). Modelagem de equações estruturais baseada em covariância (cb-sem) com o Amos. Revista Brasileira de Marketing, 13(2), 44-55. http://dx.doi.org/10.5585/remark.v13i2.2718

Heitz-Spahn, S. (2013). Cross-channel free-riding consumer behavior in a multichannel environment: An investigation of shopping motives, sociodemographics and product categories. Journal of $\begin{array}{llll}\text { Retailing } \text { and } & \text { Consumer }\end{array}$ http://dx.doi.org/10.1016/j.jretconser.2013.07.006

Jiang, L., Yang, Z., \& Jun, M. (2013). Measuring consumer perceptions of online shopping convenience. $\begin{array}{llll}\text { Journal of Service } & \text { Management, } & \text { 24(2), } & \text { 191-214. }\end{array}$ http://dx.doi.org/10.1108/09564231311323962

Nadarajah, S., \& Kotz, S. (2009). Models for purchase frequency. European Journal of Operational Research, 192(3), 1014-1026. http://dx.doi.org/10.1016/j.ejor.2007.11.034

Nakayama, M., \& Sutcliffe, N. (2009). Price, product complexity, and durability in comparison shopping. In Y. Wan (Ed.), Comparison-shopping services and agent designs (pp.74-89). London: Information Science Reference

Niranjanamurthy, M., Kavyashree, N., Jagannath, S., \& Chahar, D. (2013). Analysis of e-commerce and m-commerce: Advantages, limitations and security issues. International Journal of Advanced Research in Computer and Communication Engineering, 2(6), 2360-2370.

Oliveira-Castro, J. M., Faria, J. B., Dias, M. B., \& Coelho, D. S. (2002). Effects of task complexity on learning to skip steps: An operant analysis. Behavioural Processes, 59(2), 101-120. http://dx.doi.org/10.1016/S0376-6357(02)00087-6

Oliveira-Castro, J. M., Ferreira, D. C., Foxall, G. R., \& Schrezenmaier, T. C. (2005). Dynamics of repeat buying for packaged food products. Journal of Marketing Management, 21(1/2), 37-61. http://dx.doi.org/10.1362/0267257053166730

Pauwels, K., Leeflang, P. S. H., Teerling, M. L., \& Huizingh, K. R. E. (2011). Does online information drive offline revenues?: Only for specific products and consumer segments! Journal of Retailing, 87(1), 1-17. http://dx.doi.org/10.1016/j.jretai.2010.10.001

Pauwels, K., \& Neslin, S. A. (2015). Building with bricks and mortar: The revenue impact of opening physical stores in a multichannel environment. Journal of Retailing, 91(2), 182-197. http://dx.doi.org/10.1016/j.jretai.2015.02.001

Pierce, W. D., \& Cheney, C. D. (2013). Behavior analysis and learning. New York: Psychology Press.

Pohl, R., \& Oliveira-Castro, J. (2008). Efeitos do nível de benefício informativo das marcas sobre a duração do comportamento de procura. Revista da Administração Contemporânea Eletrônica, 2(3), 449-469. Recuperado de http://www.anpad.org.br/periodicos/arq_pdf/a_826.pdf

Pohl, R. H., Oliveira-Castro, J. M., Bertoldi, L., \& Lourenzo, A. L. (2006). Efeitos do nível de benefício utilitário sobre a duração do comportamento de procura por produtos. Revista Psicologia Organizações e Trabalho, 6(1), 233-264. 
Porto, R. B., \& Okada, S. I. (2018). Comportamento do consumidor em canais cruzados e seus benefícios: Validação de escala para avaliar o desempenho do processo de compra. Revista Brasileira de Gestão de Negócios, 20(3), 443-460. http://dx.doi.org/10.7819/rbgn.v20i3.3415

Porto, R. B., \& Oliveira-Castro, J. M. (2016). Consumer purchase and brand performance. In G. Foxall (Ed.), The Routledge companion to consumer behavior analysis (pp. 175-199). New York: Routledge.

Porto, R. B., Oliveira-Castro, J. M. D., \& Seco-Ferreira, D. C. (2011). What consumers say and do: Planned and actual amounts bought in relation to brand benefits. The Service Industries Journal, 31(15), 2559-2570. http://dx.doi.org/10.1080/02642069.2011.529607

Sanakulov, N., \& Karjaluoto, H. (2015). Consumer adoption of mobile technologies: A literature review. International Journal of Mobile Communications, 13(3), 244-275. http://dx.doi.org/10.1504/IJMC.2015.069120

Singley, R. B., \& Williams, M. R. (1995). Free riding in retail stores: An investigation of its perceived prevalence and costs. Journal of Marketing Theory and Practice, 3(2), 64-74. http://dx.doi.org/10.1080/10696679.1995.11501685

Skinner, B. F. (2013). Contingencies of reinforcement: A theoretical analysis (Vol. 3). East Norwalk, CT, USA: BF Skinner Foundation.

Stone, M., Hobbs, M., \& Khaleeli, M. (2002). Multichannel customer management: The benefits and challenges. Journal of Database Marketing \& Customer Strategy Management, 10(1), 39-52. http://dx.doi.org/10.1057/palgrave.jdm.3240093

Trenz, M. (2015). Multichannel commerce: A consumer perspective on the integration of physical and electronic channels. New York: Springer International Publishing.

Van Baal, S., \& Dach, C. (2005). Free riding and customer retention across retailers' channels. Journal of Interactive Marketing, 19(2), 75-85. http://dx.doi.org/10.1002/dir.20036

Van Nierop, J. E. M., Leeflang, P. S. H., Teerling, M. L., \&. Huizingh E. K. R. (2011). The impact of introducing and using an informational website on offline customer buying behavior. International Journal of Research in Marketing, 28(2), 155-165. http://dx.doi.org/10.1016/j.jiresmar.2011.02.002

Verhoef, P. C., Kannan, P. K., \& Inmanc, J. (2015). From multi-channel retailing to omni-channel retailing: Introduction to the special issue on multi-channel. Journal of Retailing, 91(2), 174-181. http://dx.doi.org/10.1016/j.jretai.2015.02.005

Wang, R. J. H., Malthouse, E. C., \& Krishnamurthi, L. (2015). On the go: How mobile shopping affects customer purchase behavior. Journal of Retailing, 91(2), 217-234. http://dx.doi.org/10.1016/j.jretai.2015.01.002

Xia, L., \& Monroe, K. B. (2005). Consumer information acquisition. Review of Marketing Research, 1, 101-152.

Xu, J., Forman, C., Kim, J. B., \& Van Ittersum, K. (2014). News media channels: Complements or substitutes? Evidence from mobile phone usage. Journal of Marketing, 78(4), 97-112. http://dx.doi.org/10.1509/jm.13.0198 


\section{Dados dos Autores}

Sionara Okada

Prédio da FACE, Campus Universitário Darcy Ribeiro, 70910-900, Brasília, DF, Brasil. E-mail: sionara14@gmail.com. http://orcid.org/0000-0002-3953-0629

Rafael Porto

Prédio da FACE, Campus Universitário Darcy Ribeiro, 70910-900, Brasília, DF, Brasil. E-mail: rafaelporto@unb.br. http://orcid.org/0000-0003-2210-7098 